\title{
Oil and Gas
}

Workers:

\section{How to Prevent Fatigued Driving at Work}

Oil and gas workers drive long distances from their homes, lodging sites, and equipment yards to reach well sites that are often in remote areas. The combination of long trips with long shifts can result in fatigue.

Fatigued (drowsy) driving is a major cause of crashes in this industry. Crashes are the leading cause of death for oil and gas extraction workers. This fact sheet gives drivers information about fatigue and tips to stay safe behind the wheel.

\section{Fatigued driving is linked to several factors.}

\section{Time of day}

Your natural body clock (circadian rhythm) gives strong signals that it's time to sleep at night and early morning hours. You may also experience a dip in alertness in the afternoon.

\section{Length of time awake}

The more hours awake, the more likely you are to be fatigued. Fatigue can impair your driving and other tasks, similar to alcohol impairment. If you don't get enough sleep for many days in

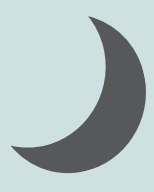
a row, you can also suffer impairment.

\section{The Reality of Fatigued Driving}

At the end of an estimated 20-hour work shift, three oil and gas workers drove from a remote work site to the employer's bunkhouse and found

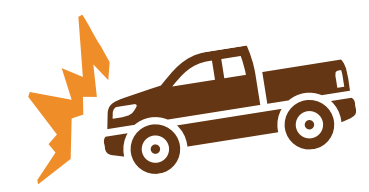
it was full. Around midnight, they began a 10-hour trip home. After only 25 miles, the driver fell asleep at the wheel. The vehicle veered off the road at a curve and rolled several times. None of the workers were wearing a seat belt and were all ejected. Two workers died.

\section{Monotonous tasks}

Driving for extended periods of time with few changes in routine can increase risk of

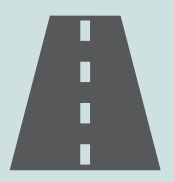
fatigued or inattentive driving.

\section{Medications and health conditions}

Illnesses, diseases, and some medications may interfere with your alertness, increasing the risk of fatigued driving.

\section{Warning Signs}

$\checkmark$ Frequent yawning

$\checkmark$ Heavy eyelids

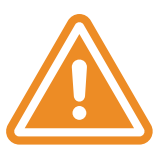

$\checkmark$ Drifting from your lane

$\checkmark$ Forgetting last few miles driven 


\section{What can workers do to}

\section{prevent fatigued driving?}

\section{Oil and gas workers: Take the following}

actions to stay safe behind the wheel.

\section{Get enough sleep.}

Stay well-rested and alert by getting 7-9 hours of sleep each day in a dark, quiet, and comfortable space.

Tell friends and family you need to get enough sleep before you start a work shift.

For long commutes, travel the day before or after your hitch begins or ends.

When extended wait times on well sites occur, get sleep on site by using rest locations if available, or create a restful environment by using ear plugs, eye masks, etc.

$\square$ Make sure you understand and follow your company's policies about fatigue management, planning travel, and hours-of-service requirements.

Plan your trip to include safe places to take rest breaks and get nutritious food.

Let others know where you will be and when. Check in regularly.

\section{Maintain good health.}

$\square$ If your job is not active, engage in physical activity two and half hours per week.

Avoid sugar-rich and low-fiber carbohydrate foods (such as cookies, sweetened drinks, white bread, pasta).

Be aware of the signs of sleep disorders, and seek screening.

Use stop work authority at any time you feel it is unsafe to continue driving. Intervene if you believe a coworker may be fatigued.

In an emergency situation where you feel tired but must drive a little longer: pull over, drink a cup of coffee, and take a nap for 15-30 minutes before continuing.

\section{Myths:}

I can use caffeine regularly to make up for lack of sleep.

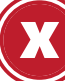

I can stay awake by rolling down

my window and turning up the radio.
National Highway Traffic Safety Administration www.nhtsa.gov/risky-driving/drowsydriving Understand the scope of the problem of drowsy driving.

\section{DrowsyDriving.org}

www.drowsydriving.org

Find warning signs and facts.
Mention of any company or product does not constitute endorsement by the National Institute for Occupational Safety and Health, Centers for Disease Control and Prevention. In addition, citations to websites external to NIOSH do not constitute NIOSH endorsement of the sponsoring organizations or their programs or products. Furthermore, $\mathrm{NIOSH}$ is not responsible for the content of these websites. All web addresses referenced in this document were accessible as of the publication date. DHHS (NIOSH) Publication No. 2018-126 https://doi.org/10.26616/NIOSHPUB2018126 March 2018 